\title{
Cost-effectiveness analysis for priority setting in health: Penny-wise but pound-foolish
}

\author{
Rob Baltussen, Werner Brouwer, Louis Niessen \\ Erasmus Medical Centre Rotterdam
}

\begin{abstract}
Cost-effectiveness analysis has much conceptual attractiveness in priority setting but is not used to its full potential to assist policy-makers on making choices in health in developed or in developing countries. We call for a shift away from present economic evaluation activities - that tend to produce ad hoc and incomparable economic evaluation studies and, therefore, add little to the compendium of knowledge of cost-effectiveness of health interventions in general-toward a more systematic approach. Research efforts in economic evaluation should build on the foundations of cost-effectiveness research of the past decades to arrive at an informative methodology useful for national policy-makers. This strategy means that governments should steer sectoral cost-effectiveness analysis to obtain systematic and comprehensive information on the economic attractiveness of a set of new and current interventions, using a standardized methodology and capturing interactions between interventions. Without redirecting the focus of economic evaluation research, choosing in health care bears the risk to remain penny-wise but pound-foolish.
\end{abstract}

Keywords: Cost-effectiveness, Economic evaluation, Priority setting, Methodology

Cost-effectiveness analysis (CEA) has often been proposed to guide priority setting in health but is not used to its full potential in developed or in developing countries. In the absence of central guidance, present research is dominated by studies of new interventions compared with current practice, without referral to the question of which interventions are most important to evaluate or the appropriateness of current practice. This absence provides policy-makers with incomprehensive or even misleading information to guide allocation decisions in health.

If economic evaluation is to facilitate the process of priority setting effectively, a clear vision of what needs to be achieved and how this can be done is required. Here, we propose a reformulation of economic evaluation appropriate for the challenges in priority setting.

\section{THE PRACTICE OF COST-EFFECTIVENESS ANALYSIS}

The technique of economic evaluation has much conceptual attractiveness in priority setting, because it relates the achievable health gain of interventions with the costs of these interventions. Thus, comparable costs per life years gained or costs per quality-adjusted life year gained should result. The central notion behind these exercises is that health resources should be allocated across interventions and population groups in such as way that the most health is generated with the available budget. The health potential for the application of economic evaluation is high. For example, an analysis for East Africa suggested that a reallocation of 50 percent of the health budget (approximately US $\$ 5.20$ per capita) from interventions that are not cost-effective (i.e., have high costs per life year gained) toward those that are most costeffective (i.e., have low costs per life year gained) could result in a 64 percent increase in the years of life saved in the region (1).

Economic evaluation of health-care technologies has been formally institutionalized in the priority setting process in several countries, including United Kingdom, The Netherlands, Sweden, and New Zealand/Australia. In developing countries, the 1993 World Development Report "Investing in Health" (8) sparked off significant interest in CEA as an aid to priority setting in, for example, Mexico, India, and a set of East and Northern African countries. However, its impact on decision making is quite limited (14). Disagreements over the theoretical bases of the methods and quality of the available empirical evidence are important in this respect (14). However, a more fundamental flaw, we argue, is 
the lack of central guidance in present economic evaluation research. This finding causes at least three large drawbacks.

First, research priorities do rarely follow explicit criteria such as burden of disease or potential societal benefit but typically result from ad hoc decisions, bottom-up approaches, or interests of pharmaceutical companies. The resulting compendium of CEA, therefore, is far from comprehensive and may omit important interventions from the societal point of view. For example, systematic reviews on effectiveness and cost-effectiveness of brachytherapy for prostate cancer (11) and growth therapy for children (2) could not identify any single economic evaluation study, although the use of these interventions is increasing. Likewise, Churchill and colleagues (3) describe an "overall paucity of economic data available for analysis and interpretation" in the area of depression. On the other hand, a systematic review on the cost-effectiveness of colorectal screening identified 180 potential articles (13). This unbalanced set of evaluated interventions does not allow policy-makers to make allocation decisions across a disease area, let alone across the entire health sector. This is reinforced by the emphasis of current CEA research to compare new interventions with current practice, which ignores the question of whether current interventions themselves are cost-effective (10). Therefore, the current information may lead to strategies and information that helps us to be pennywise but rarely corrects us in being pound-foolish.

Second, different CEA results are difficult to compare because of the lack of standardization in study methodology. A systematic review of CEA in rheumatoid arthritis remained inconclusive because "studies lack consistency in their accounting frameworks" (18). Similar conclusions were drawn in the area of neurology (7) and diabetes mellitus (9).

Third, CEAs typically evaluate one intervention at a time. Given that normally a health-care system delivers numerous interventions, it is important to note that many interactions between interventions in terms of costs and effects will be present but cannot be accounted for in isolated CEAs. For example, passive case detection and DOTS treatment interacts with $\mathrm{BCG}$ vaccination in terms of costs and outcomes (10).

\section{A NEED FOR REGULATION}

The collection of cost-effectiveness information on health technologies can be seen as a public good that cannot be left to individual (market) entities in the health-care sector and for which collective action is required (19). Therefore, we see a clear need for regulation in economic evaluation research in defining research priorities, funding research, and facilitating technical guidance to the execution of the analysis. Governments should foster economic analysis that results in an overview of economic attractiveness of a comprehensive set of new and current interventions. Only a systematic approach will allow governments to maximize health gains from a given budget by ceasing the funding of interventions that are not cost-effective and by spending more resources on interventions that are cost-effective.

Governmental action and institutional support (19) is required to initiate a systematic approach to economic analysis. The public funding of so-called Horizon Scanning Systemsthat aim to identify and assess potentially significant technologies for health and health care that might become available on the market in 0 to 5 years time - in many Western countries is one important step forward in the systematic interpretation of cost-effectiveness evidence (5). However, we argue that national public bodies should also regulate and coordinate the initiation and execution of economic evaluation research to better address information needs of policymakers, as exemplified by the National Institute of Clinical Excellence (NICE) in the United Kingdom (6) and the demand for a similar body in The Netherlands (15)

\section{DO NOT LET THE PERFECT BE THE ENEMY OF THE GOOD}

The required cost-effectiveness information should be seen as only one input into the policy debate on priorities, which includes several other criteria reflecting goals of health systems (10). Given the multiple goals in health care, rather than a formulaic approach, economic analysis is probably most powerful when it is ultimately used to classify interventions into broad groups of cost-effectiveness: those that are very cost-effective, cost-effective, and not cost-effective. The use of cost-effectiveness thresholds basically reflect this way of thinking by setting a maximum cost per QALY, which is meant to separate the cost-effective from the cost-ineffective interventions (4). In this context, instead of striving for detailed estimates, which often result from prospective analysis, analysts can suffice to provide results that prove the "order of magnitude" of cost-effectiveness of interventions.

\section{SECTORAL COST-EFFECTIVENESS ANALYSIS}

A national compendium on cost-effectiveness would require the joint evaluation of interventions in a single exercise to avoid methodological inconsistencies and the neglect of interactions between diseases and/or interventions. Such a comprehensive approach to economic evaluation already has been proposed by Weinstein and Stason (21) in their foundations of CEA, more than 25 years ago, and has been labeled sectoral CEA by others $(10 ; 16)$. Sectoral CEA is essentially the result of a combination of many individual CEA, but central guidance and standardization allow the integration of studies and comparability of results. The resulting costeffectiveness database, thereby, is much different from many published cost-effectiveness league tables, which essentially face the same limitations as the economic analyses they are based on (as discussed above). Given its conceptual attractiveness, it is striking that only a few applications of sectoral 
CEA exist. Work in Western countries includes that of the Oregon Health Services Commission (12), the Harvard Life Saving Project (20) in the United States, and-to a certain extent-NICE in the United Kingdom (6). For developing countries, the World Bank Health Sector Priorities Review (8) and the WHO-CHOICE (CHOosing Interventions that are Cost-Effective) project (17) carried out global and regional analysis.

\section{CONCLUSION}

The need to make choices in health is visible but present economic evaluation research is incapable to support decisions. We call for a shift away from present economic evaluation activities - that tend to produce ad hoc and incomparable economic evaluation studies and, therefore, add little to the compendium of knowledge of cost-effectiveness of health interventions in general - toward a more systematic approach to economic evaluation research. Countries that have the financial and analytical means may wish to adopt a NICE-like approach, whereas resource-poor countries may adopt a more rudimentary approach and draw their knowledge from global and regional databases. It is time to expand our research efforts in economic evaluation and build on the foundations of cost-effectiveness research of the past decades to arrive at an informative methodology useful for national policy-makers. Without redirecting the focus of this research, choosing in health-care bears the risk to remain penny-wise but poundfoolish.

\section{CONTACT INFORMATION}

Rob Baltussen, PhD (r.baltussen@erasmusmc.nl), Werner Brouwer,PhD (w.brouwer@erasmusmc.nl), Louis Niessen, PhD (1.niessen@erasmusmc.nl), Institute for Medical Technology Assessment (iMTA), Erasmus Medical Centre Rotterdam, P.O. Box 1738, 3000 DR Rotterdam, The Netherlands

\section{REFERENCES}

1. Bobadilla JL, Cowley P, Musgrove P, Saxenian H. Design, content and financing of an essential national package of health services. Bull World Health Organ. 1994;72:653-662.

2. Bryant J, Cave C, Mihaylova B, et al. Clinical effectiveness and cost-effectiveness of growth hormone in children: A systematic review and economic evaluation. Health Technol Assess. 2002;6:1-168.

3. Churchill RHV, Corney R, Knapp M, et al. A systematic review of controlled trials of the effectiveness and cost-effectiveness of brief psychological treatments for depression. Health Technol Assess. 2001;5:1-173.
4. Eichler HG, Kong SX, Gerth WC, Mavros P, Jonsson B. Use of cost-effectiveness analysis in health-care resource allocation decision-making: How are cost-effectiveness thresholds expected to emerge? Value Health. 2004;7:518-528.

5. EuroScan. The European Information Network on New and Changing Health Technologies. Available at: http://www. publichealth.bham.ac.uk/euroscan/members/current.htm. Accessed May 15, 2005.

6. Gafni A, Birch S. NICE methodological guidelines and decision making in the National Health Service in England and Wales. Pharmacoeconomics. 2003;21:149-157.

7. Holloway RG, Benesch CG, Rahilly CR, Courtright CE. A systematic review of cost-effectiveness research of stroke evaluation and treatment. Stroke. 1999;30:1340-1349.

8. Jamison DT, Mosley WH, Measham AR, Bobadilla JL. Disease control priorities in developing countries. New York: Oxford University Press; 1993.

9. Klonoff DC, Schwartz DM. An economic analysis of interventions for diabetes. Diabetes Care 2000;23:390-404.

10. Murray CJ, Evans DB, Acharya A, Baltussen RM. Development of WHO guidelines on generalized cost-effectiveness analysis. Health Econ. 2000;9:235-251.

11. Norderhaug I, Dahl O, Hoisaeter PA, et al. Brachytherapy for prostate cancer: A systematic review of clinical and cost effectiveness. Eur Urol. 2003;44:40-46.

12. Oregon, HSC. Oregon Medicaid priority setting project. Eugene: Oregon State Government; 1991.

13. Pignone M, Saha S, Hoerger T, Mandelblatt J. Cost-effectiveness analyses of colorectal cancer screening: A systematic review for the U.S. Preventive Services Task Force. Ann Intern Med. 2002;137:96-104.

14. Robinson R. Limits to rationality: Economics, economists and priority setting. Health Policy. 1999;49:13-26.

15. Rutten FF, Brouwer WB. Meer zorg bij beperkt budget; een pleidooi voor een betere inzet van het doelmatigheidscriterium (in Dutch). Ned Tijdsch v Geneesk. 2002;146:2254-2258.

16. Stinnett AA, Paltiel AD. Mathematical programming for the efficient allocation of health care resources. $J$ Health Econ. 1996;15:641-653.

17. Tan Torres $\mathrm{T}$, Baltussen R, Adam T. et al. WHO guide to cost-effectiveness analysis. Geneva: World Health Organization; 2003.

18. Tella MN, Feinglass J, Chang RW. Cost-effectiveness, costutility, and cost-benefit studies in rheumatology: A review of the literature, 2001-2002. Curr Opin Rheumatol. 2003;15:127131.

19. Tenbesnel T. Interpreting public input into priority-setting: The role of mediating institutions. Health Policy. 2002;62:173194.

20. Tengs TO, Adams ME, Pliskin JS, et al. Five-hundred lifesaving interventions and their cost-effectiveness. Risk Anal. 1995; 15:369-390.

21. Weinstein MC, Stason WB. Foundations of cost-effectiveness analysis for health and medical practices. $N$ Engl J Med. 1977;296:716-721. 